\title{
ROLE OF MRI IN EVALUATION OF SUSPECTED SPINAL DYSRAPHISM
}

\author{
M. Vijaya Kumari ${ }^{1}$ P. Supriya², Suman Chandra Aemjal ${ }^{3}$, Raghavendra $Y^{4}$ \\ ${ }^{1}$ Associate Professor, Department of Radiodiagnosis, Osmania General Hospital. \\ 2In Service Post Graduate, Department of Radiodiagnosis, Osmania General Hospital. \\ 3Professor, Department of Radiodiagnosis, Osmania General Hospital. \\ ${ }^{4}$ Junior Resident, Department of Radiodiagnosis, Osmania General Hospital.
}

\section{ABSTRACT}

Congenital abnormalities of the spine and spinal cord are referred to as spinal dysraphisms. Spinal dysraphisms can be broadly categorized into open and closed type. This can be grouped as open if the overlying skin is not intact causing leakage of cer ebrospinal fluid and occult if the defect is well covered with full thickness skin. The surgical outcome may be better if intervention occurs before the age of 3 years.

Spinal neuroimaging therefore has the important role of determining the presence or absence of an occult spinal dysraphic lesion, so that appropriate surgical treatment can be instituted in a timely manner. MRI is the imaging modality of choice to demonstrate the spectrum of findings in patients with suspected spinal dysraphism, because of its better diagnostic performance, excellent soft tissue characterization and importance in pre-surgical planning.

\section{AIMS}

To demonstrate the spectrum of MRI findings in spinal dysraphism.

\section{MATERIALS AND METHODS}

Prospective evaluation of 66 patients with suspected spinal dysraphism on 1.5 T MRI.

\section{RESULTS}

Age of the patients ranged from 17 days to 13 years. Commonest clinical presentation was swelling in the back. Open spinal dysraphism, in which lumbosacral myelomeningocele was most common presentation. Diastematomyelia was the next most common presentation. Associated abnormalities like hydrocephalus, Arnold-Chiari, syrinx, hydronephrosis were commonly encountered in open defects. We have one case of open spinal dysraphism with osseous hamartoma. MRI with its multiplanar capabilities and superior soft tissue contrast, allows detection of detailed anatomy and characterization of congenital spinal disorders.

\section{CONCLUSION}

MRI is an excellent imaging modality for visualizing the spinal cord at all ages and is the imaging modality of choice for defining complex spinal dysraphism.

\section{KEYWORDS}

MRI, Spinal Dysraphism, Lumbar Myelomeningocele, Diastematomyelia, Open Spinal Dysraphism with Osseous Hamartoma, Tethered Cord, Dermal Sinus.

HOW TO CITE THIS ARTICLE: Kumari MV, Supriya P, Aemjal SC, et al. Role of MRI in evaluation of suspected spinal dysraphism. J. Evolution Med. Dent. Sci. 2016;5(17):879-884, DOI: 10.14260/jemds/2016/203

\section{INTRODUCTION}

Congenital abnormalities of the spine and spinal cord are referred to as spinal dysraphisms. Spinal dysraphisms can be broadly categorized into open and closed type. This can be grouped as open if the overlying skin is not intact causing leakage of cerebrospinal fluid and occult if the defect is well covered with full thickness skin. The estimated incidence of spinal dysraphism is about 1-3/1000 live birth. About 55-70\% of neural tube defects occur in females. Early detection and prompt neurosurgical correction of occult spinal dysraphism may prevent upper urinary tract deterioration, infection of dorsal dermal sinuses or permanent neurologic damage. The surgical outcome may be better if intervention occurs before the age of 3 years.

Financial or Other, Competing Interest: None.

Submission 09-01-2016, Peer Review 08-02-2016,

Acceptance 15-02-2016, Published 29-02-2016.

Corresponding Author:

Dr. Raghavendra $Y$.

Junior Resident,

Osmania General Hospital, Hyderabad.

E-mail: dr.raghavan08@gmail.com

DOI: $10.14260 /$ jemds $/ 2016 / 203$
Spinal neuroimaging, therefore, has the important role of determining the presence or absence of an occult spinal dysraphic lesion, so that appropriate surgical treatment can be instituted in a timely manner. Magnetic Resonance Imaging (MRI) is the examination of choice because of its better diagnostic performance, excellent soft tissue characterization and importance in presurgical planning.

\section{MATERIALS AND METHODS}

We prospectively evaluated 66 patients with suspected spinal dysraphism and who had undergone MR imaging of the spine from May 2012 to September 2014 were included in the study after informed consent.

\section{Inclusion Criteria}

Patients who presented with various neurological problems and skin stigmata suspicious of spinal dysraphism.

\section{Exclusion Criteria}

Patients with metallic implants and patients with claustrophobia were excluded from the study. In all patients clinical history and antenatal history were recorded. Sedation was given in required patients. 
MRI was performed on a 1.5 Tesla electromagnet (General Electrical Medical Systems). The pulse sequences included T1WI, T2WI using spin echo and Short Tau Inversion Recovery sequences. Axial and sagittal T2WI were obtained with TR of $3000 \mathrm{~ms}$ and TE of $120 \mathrm{~ms}$. Sagittal T1WI were obtained with TR of $60 \mathrm{~ms}$ and TE of $30 \mathrm{~ms}$. Sagittal and coronal STIR images were obtained with TR of $3000 \mathrm{~ms}$ and TE of $40 \mathrm{~ms}$. Images were obtained with an interslice gap of $5.2 \mathrm{~mm}$, slice thickness of $4 \mathrm{~mm}$ and a matrix size of $512 \times 512$. On MRI, imaging findings in vertebrae, spinal cord and soft tissues were noted.

\section{OBSERVATIONS AND RESULTS}

66 patients who presented with various neurological problems and skin stigmata suspicious of spinal dysraphism were referred to our department in Osmania General Hospital and underwent Magnetic Resonance Imaging of the spine in a time period from May 2012 to September 2014 were included in our study. Age of the patients ranged from 17 days to $13 \mathrm{yrs}$. Most of the children are below 1 yr. of age. Of the 66 patients, 40 were female patients and 26 were male patients. The below table shows the gender distribution of spinal dysraphism.

\begin{tabular}{|c|c|c|}
\hline GENDER & NUMBER & PERCENTAGE \\
\hline Males & 26 & $39.4 \%$ \\
\hline Females & 40 & $60.6 \%$ \\
\hline \multicolumn{3}{|c|}{ Table 1: Gender Distribution } \\
\hline
\end{tabular}

Of the 66 patients, 38 are open spinal dysraphisms and 28 are closed dysraphisms.

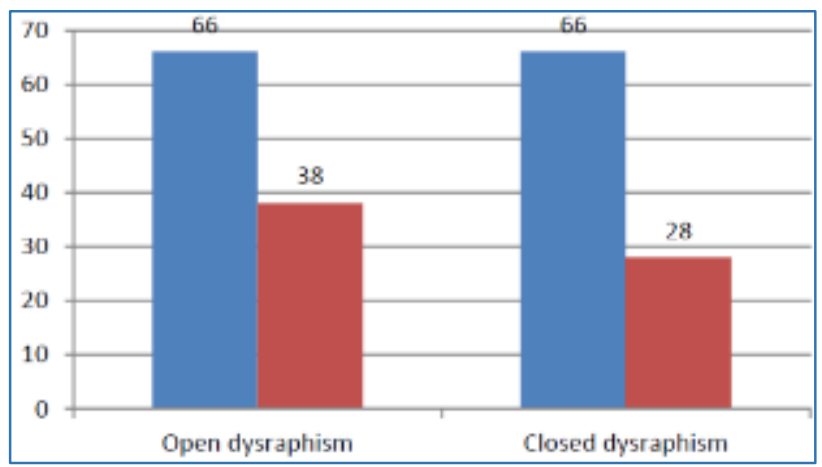

Fig. 1: Types of Spinal Dysraphism

Children with suspected spinal dysraphism can present with various clinical features such as swelling on the back, dimple, hemangioma, dermal sinus, lower limb weakness, bladder and bowel incontinence.

\begin{tabular}{|c|c|c|c|}
\hline Sl. No. & Clinical Feature & Number & Percentage \\
\hline 1. & Swelling in the back & 51 & $77.2 \%$ \\
2. & Hypertrichosis & 6 & $9 \%$ \\
3. & Dimple & 3 & $4.5 \%$ \\
4. & Lower & 14 & $21.2 \%$ \\
5. & Limb weakness & 6 & $9 \%$ \\
6. & Urinary incontinence & 4 & $6 \%$ \\
7. & Dermal sinus & 2 & $3 \%$ \\
\multicolumn{4}{|c|}{ Table 2: Clinical Presentation of Spinal Dysraphism } \\
\hline
\end{tabular}

Myelomeningocele followed by diastematomyelia were the commonest presentations in our study. One case was cervical myelomeningocele with osseous hamartoma.

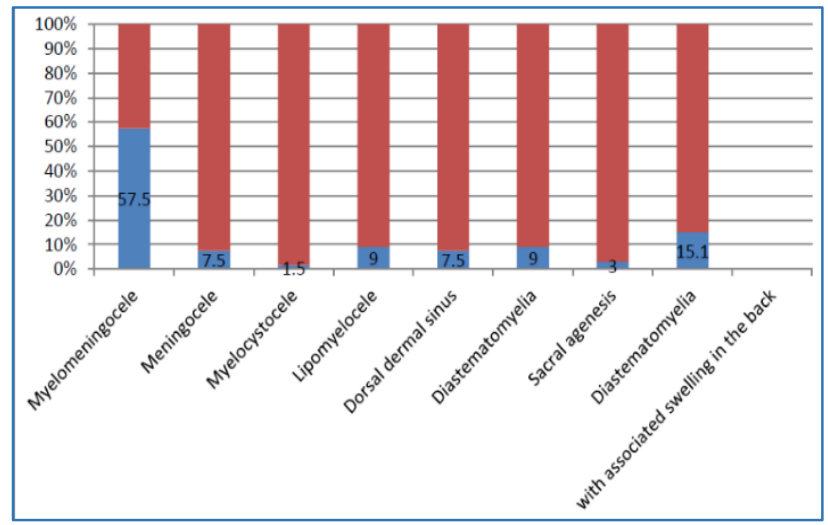

Fig. 2: Different Types of Dysraphism

Location of myelomeningoceles of the 38 patients in our study, 4 were noted in the cervical region, 2 in the dorsal region, 5 in the lumbar region, 7 in the sacral region, 20 in lumbosacral region and 2 in dorsal region.

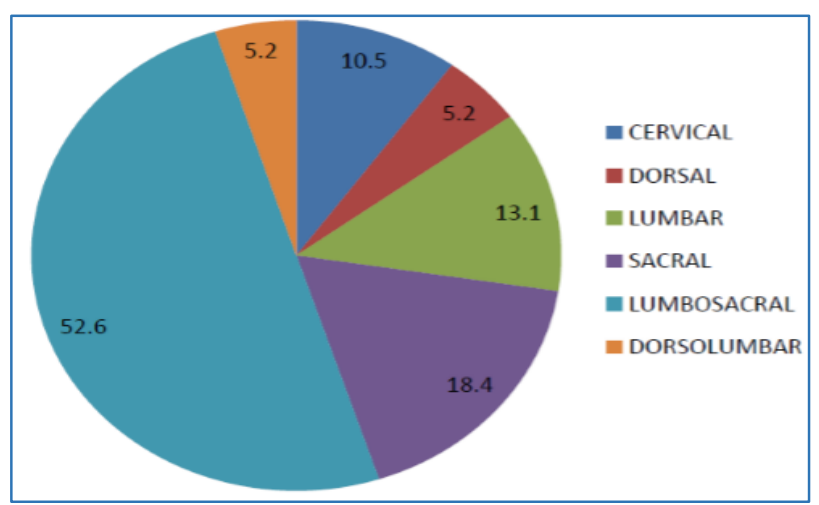

Fig. 2: Location of Myelomeningoceles

Of 66 patients, 16 Diastematomyelia patients were detected. In type 1, two hemicords are encased in respective dural sacs and separated by a bony septum. In type 2, the hemicords are encased in a single sac and separated by a fibrous septum.

\begin{tabular}{|c|c|c|c|}
\hline Sl. No. & $\begin{array}{c}\text { Type of } \\
\text { Diastematomyelia }\end{array}$ & Number & Percentage \\
\hline 1. & Type- 1 & 4 & $25 \%$ \\
2. & Type- 2 & 12 & $75 \%$ \\
\hline \multicolumn{3}{|c|}{ Table 3: Type of Diastematomyelia } \\
\hline
\end{tabular}

Open defects were associated with abnormalities such as hydrocephalus, Arnold-Chiari, syrinx.

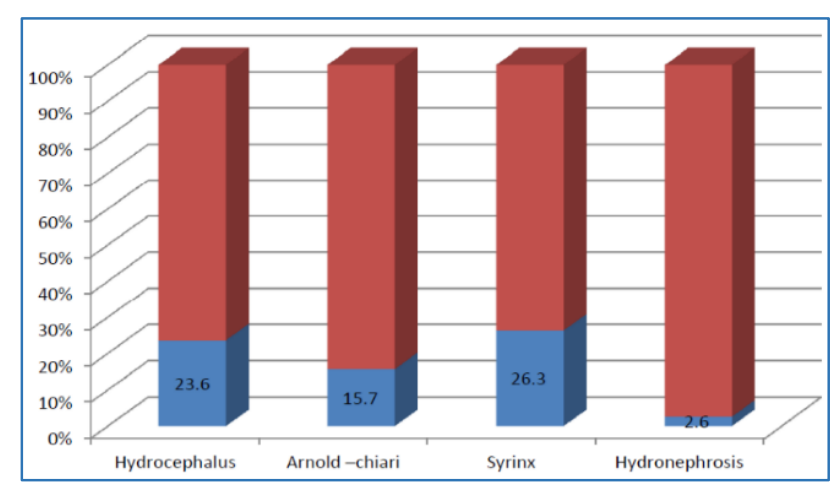

Fig. 4: Open Defects with Associated Abnormalities 
Closed defects were associated with abnormalities such as segmentation anomalies, syrinx, scoliosis, tethered cord.

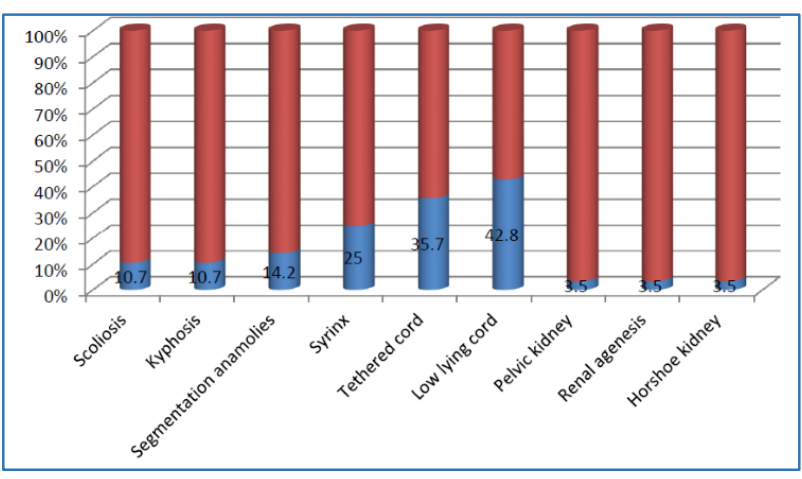

Fig. 5: Closed Defects with Associated Abnormalities

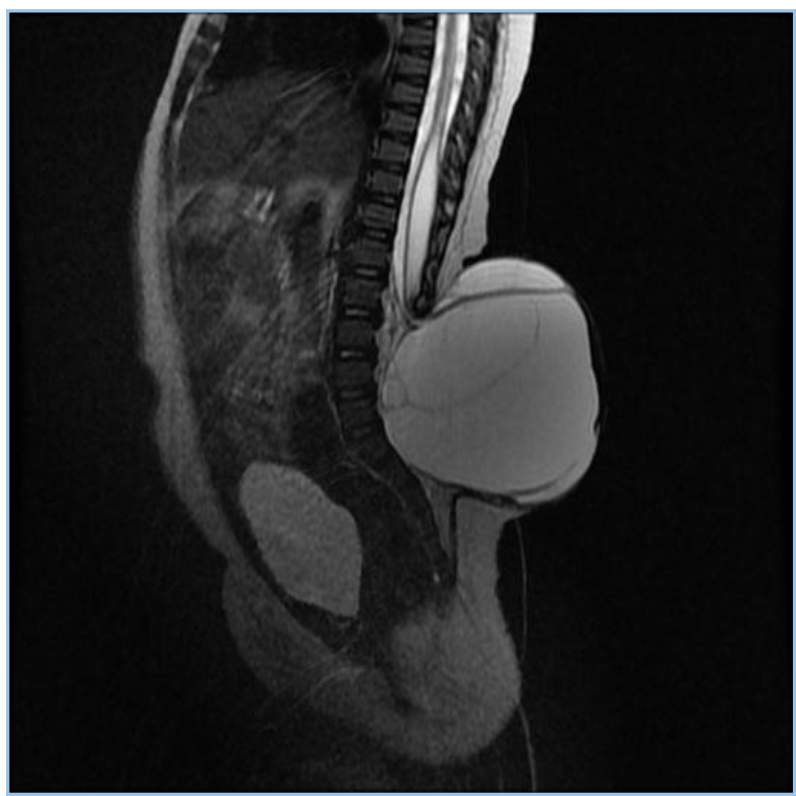

Tethered cord can result from variety of conditions. In our study, 10 cases are associated with closed spinal defects and 4 cases are due to surgery for myelomeningocele.

\begin{tabular}{|c|c|c|c|}
\hline $\begin{array}{r}\text { Sl. } \\
\text { No. }\end{array}$ & Tethered cord & Number & Percentage \\
\hline 1. & Associated with closed & 10 & $71.5 \%$ \\
2. & $\begin{array}{c}\text { defects } \\
\text { Post Surgery }\end{array}$ & 4 & $28.5 \%$ \\
\hline \multicolumn{3}{|c|}{ Table 4: Tethered Cord } \\
\hline
\end{tabular}

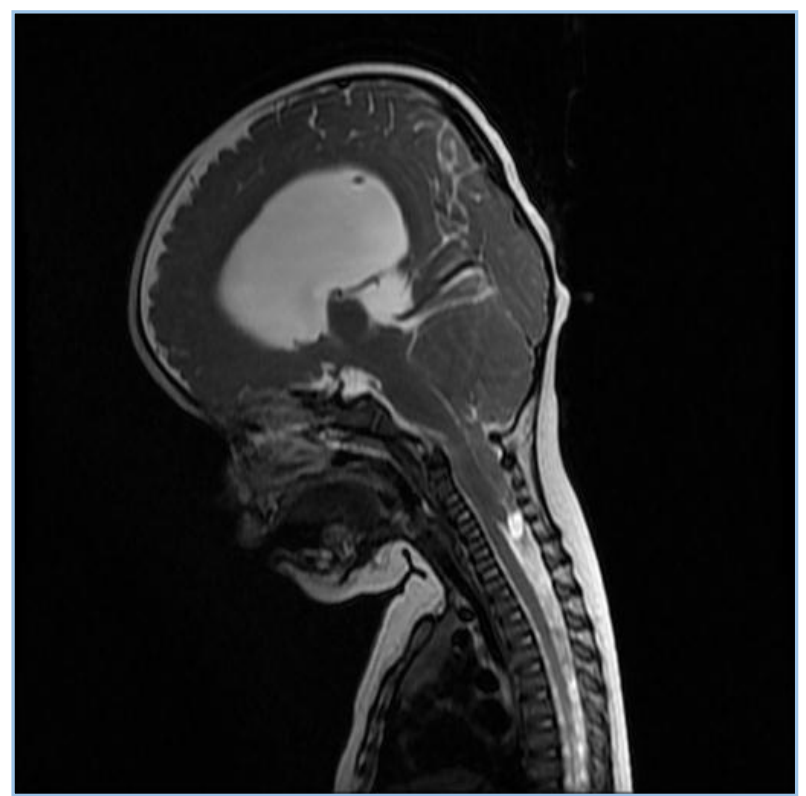

Fig. 6: Sagittal T2WI - Images showing the Herniation of Meninges and Nerve Roots into the Subcutaneous Plane and Tonsillar Herniation - Lumbar Myelomeningocele with Arnold Chiari Type 2
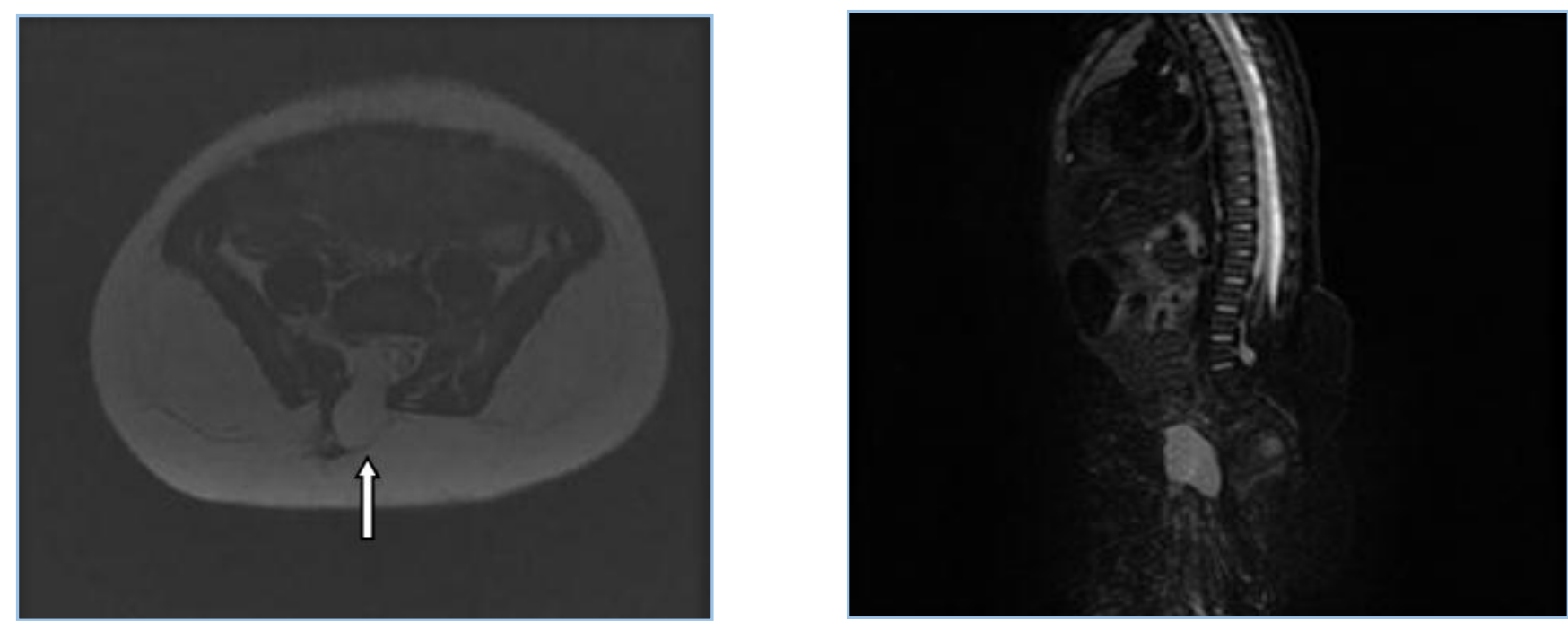

Fig. 7: Axial T2W - Images showing Herniation of Nerve Roots and Altered Signal Intensity Mass Noted in Epidural Space showing Continuity with Subcutaneous Fat. Sagittal STIR - Suppression of the Lesion - Lipomyelocele 


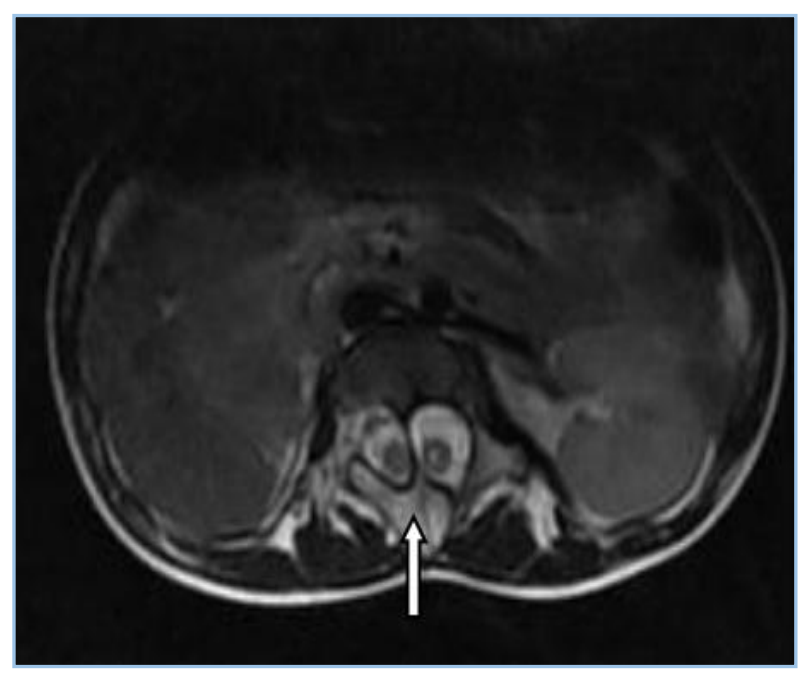

Fig. 8: Coronal STIR and Axial T2W Images showing Two Hemicords with Two Dural Sacs with Bony Septum between them with Absent Right Kidney - Diastematomyelia Type 1
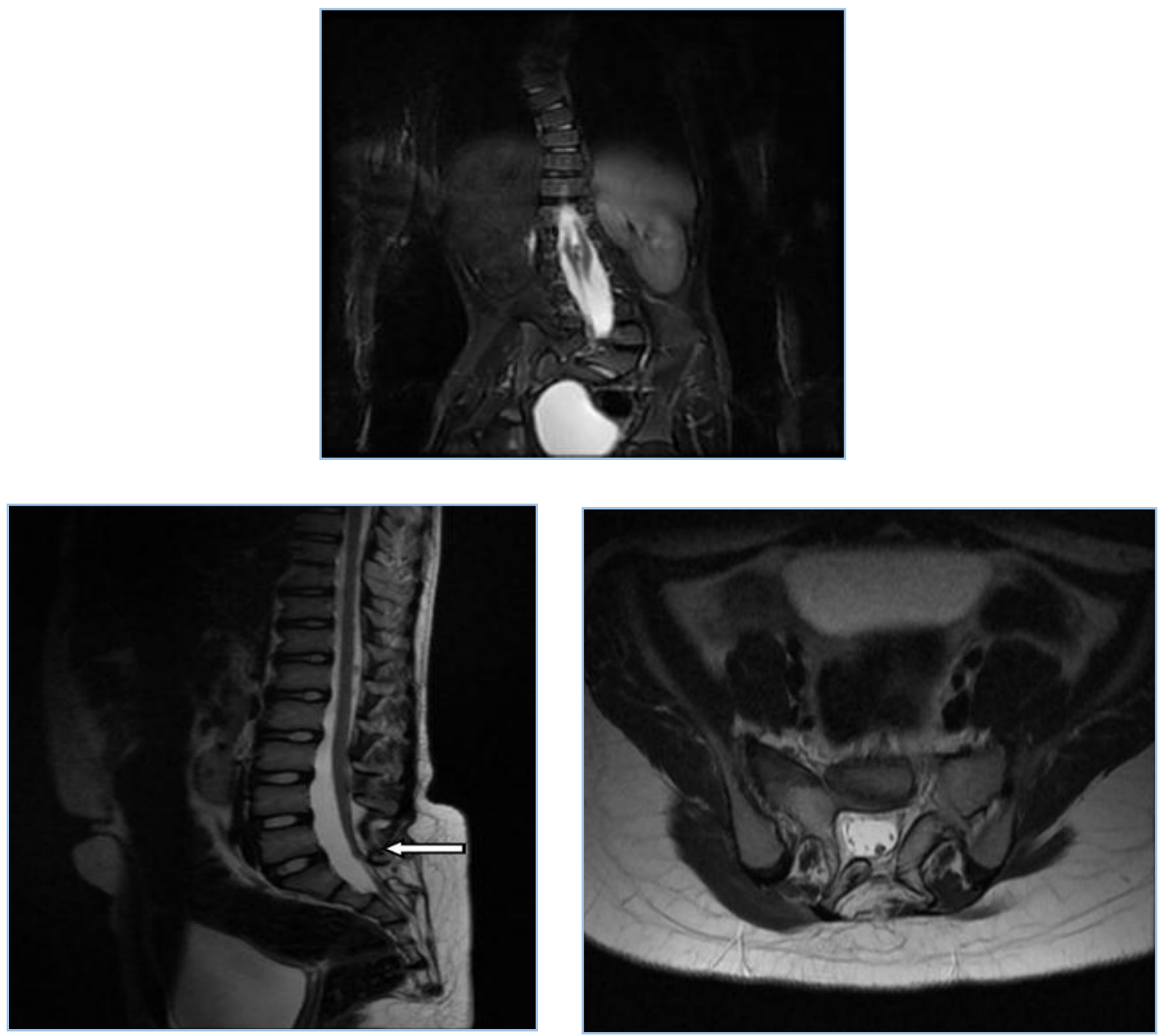

Fig. 9: Sagittal and Axial T2W Images showing Spina Bifida of L5 and S1 Vertebrae with Low Lying and Tethering of Cord - Spina Bifida with Low Lying and Tethered Cord with Thick Filum 

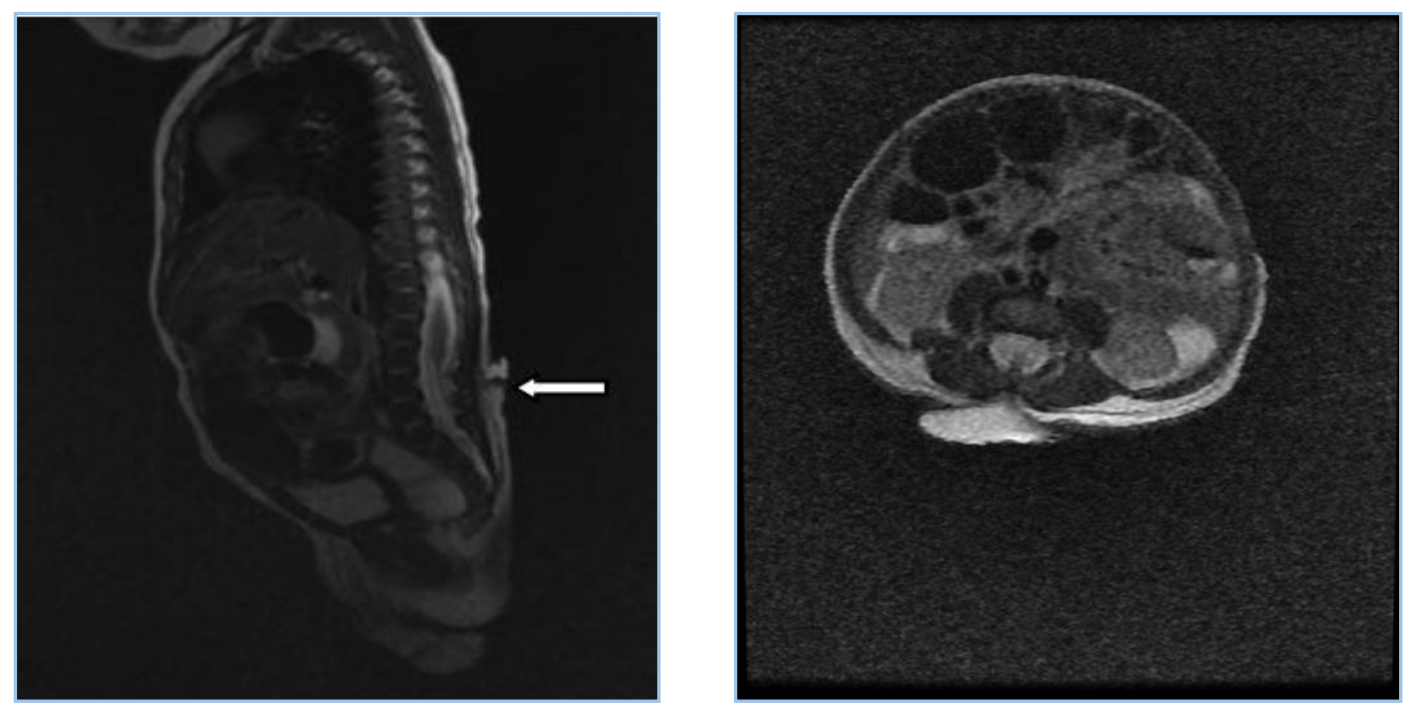

Fig. 10: Sagittal and Axial T2WI showing Hypointense Linear Structure Extending from Skin and Subcutaneous Planes at L4 Level into the Dura s/o Dorsal Dermal Sinus
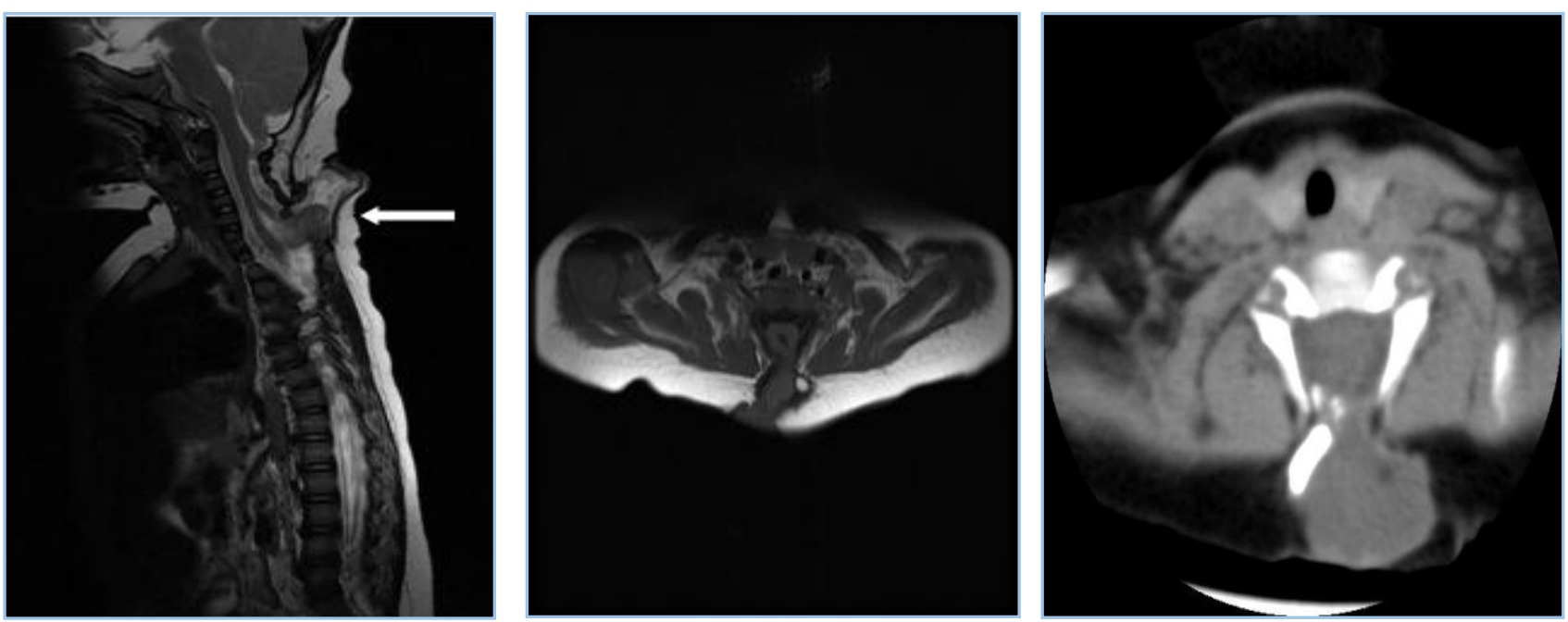

Fig. 11: Sagittal T2WI and Axial T1WI showing Herniation of Spinal Cord and Meninges. Axial CT showing Osseous Component - Cervical Myelomeningocele with Osseous Hamartoma

\section{DISCUSSION}

Congenital abnormalities of the spine and spinal cord are referred to as spinal dysraphisms. The purpose of MR imaging in spinal dysraphism is (a) Detection of detailed anatomy (b) For soft tissue characterization of lesion (c) For presurgical planning (d) For early detection and prompt neurosurgical correction of occult spinal dysraphism in order to prevent permanent neurological damage. Our study of role of MRI in evaluation of suspected spinal dysraphism consisted of 66 patients who presented to our hospital with suspected spinal dysraphism and underwent MR imaging of the spine.

The age of the patients in our study ranged from 17 days to 13 yrs. Most of the children are below $1 \mathrm{yr}$ of age. In a study by Muhammed Nafees, et al. age of the patients ranged from 16 days old to 37 yrs. old, most of them below 6.4 yrs. ${ }^{1}$ In our study, of the 66 patients $40(66.6 \%)$ were female patients and $26(33.3 \%)$ were male patients similar to study by Mohamed Fathy Dawodh et al., in which 18 are female patients and 14 are male patients. ${ }^{2}$
In our study of the 66 patients, $38(57.5 \%)$ are open spinal dysraphisms and 28 (42.4\%) are closed dysraphisms. The results were similar to study by Mohamed Fathy Dawodh et al.; 18 are open dysraphism and 14 are closed dysraphism. ${ }^{2}$

Children with suspected spinal dysraphism can present with various clinical features such as swelling on the back, dimple, hemangioma, dermal sinus, lower limb weakness, bladder and bowel incontinence. In our study, swelling in the back is the commonest clinical feature which constituted 51 (77.2\%). In a study by Mohamed Fathy Dawodh, et al., swelling in the back is the commonest clinical feature which constituted $26(81.2 \%)$. In a study by Kumar R, Singh SN, et al. swelling in the back is the commonest clinical feature which constituted $89(57 \%) \cdot 2,3$

Among different types of dysraphism myelomeningocele is the commonest. In our study, myelomeningocele constituted 38 (57.5\%). In a study by Mohamed Fathy Dawodh, et al., myelomeningocele is the commonest dysraphism which constituted $15(46.8 \%)$. 
In a study by Muhammed Nafees, et al. myelomeningocele is the commonest dysraphism which constituted $29(39.2 \%)^{2,1}$

Location of myelomeningoceles of the 38 patients in our study, 4 were noted in the cervical region, 2 in the dorsal region, 5 in the lumbar region, 7 in the sacral region, 20 in lumbosacral region and 2 in dorsal region. Among these lumbosacral region is the commonest location, which constituted 20 (52.6\%). In a study by Muhammed Nafees et al., lumbosacral region is the commonest location which constituted 38 (51.4\%). In a study by Mohamed Fathy Dawodh et al., lumbosacral region is the commonest location which constituted $11(73.3 \%))^{1,2}$

In our study of the 66 patients, 16 (24.2\%) Diastematomyelia patients were detected. Of which type 2 constituted $75 \%$ and type 1 constituted $25 \%$. In a study by Taahira Nishtar et al., of the 53 patients $2(4 \%)$ Diastematomyelia patients were detected. ${ }^{4}$

Open defects are associated with abnormalities such as hydrocephalus, Arnold-Chiari, syrinx. In our study hydrocephalus constituted 9 (23.6\%), Arnold-Chiari type 2 constituted 6 (15.7\%). In a study by Kumar R, Singh SN, et al., hydrocephalus constituted 71 (49\%), Arnold-Chiari type 2 constituted $62(45 \%))^{3}$

We had a rare case of cervical myelomeningocele with osseous dysraphic hamartoma. Zuppani HB, et al. reported a case of lipomyelocele with osseous dysraphic hamartoma in a child. ${ }^{5}$

A prospective study at NUR Research Centre Institute of Nuclear Medicine and Allied Sciences, Lucknow Marg, Delhi, Dept. of Neurosurgery, GB Pant Hospital New Delhi, was carried out in 100 cases of suspected occult spinal dysraphic anomalies with MRI in order to determine its diagnostic efficacy as the initial imaging modality. MR imaging provided accurate preoperative information in 91 out of 92 cases (98.9\%). It is concluded that MRI is an excellent primary diagnostic tool, together with a plain radiograph for complete preoperative evaluation of mid-line spinal anomalies.

Comparing with the above mentioned studies, our study revealed that MRI is imaging modality of choice to demonstrate the spectrum of findings in patients with suspected spinal dysraphism.

\section{CONCLUSION}

MRI features of 65 patients with suspected spinal dysraphism were studied and imaging findings were interpreted.

1. The age of the patients in our study ranged from 17 days to 13 yrs. Most of the children are below 1 yr. of age.
2. Female predominance was noted in our study, which constituted $66.6 \%$.

3. Open defects (57.5\%) predominated in our study than closed defects (42.4\%).

4. Swelling in the back is the commonest clinical feature in our study, which constituted 51 (77.2\%).

5. Myelomeningocele is the commonest type of dysraphism, which constituted 38 (57.5\%).

6. In myelomeningoceles, lumbosacral region is the commonest location which constituted 20 (52.6\%).

7. In our study, 16 (24.2\%) Diastematomyelia patients were detected. Of which type 2 constituted $75 \%$ and type 1 constituted $25 \%$.

8. Open defects are associated with abnormalities such as hydrocephalus, Arnold-Chiari syrinx. Other spinal cord abnormalities such as tethered cord, low lying cord, segmentation anomalies, scoliosis, kyphosis were well delineated in our study.

9. Most of the myelomeningoceles in our study are associated with abnormalities.

Hence, MRI with its multiplanar capabilities and superior soft tissue contrast, allows detection of detailed anatomy and characterization of congenital spinal disorders.

MRI is an excellent imaging modality for visualizing the spinal cord at all ages and is the imaging modality of choice for defining complex spinal dysraphism.

\section{REFERENCES}

1. Muhammad Nafees, Muhammad Hamid Akram, et al. MR image spectrum of spinal dysraphism in a military hospital in journal of army medical corps. Issue Year: 2012, Issue Number: 1, Issue Month: March.

2. Mohammed Fathy Dawoud, et al. Role of MRI in diagnosis of spinal congenital anomalies. Radiology and neurosurgery, Tanta Medical Sciences Journal, Vol (2), No (1), January 2007; PP 182-193.

3. Raj Kumar, Singh SN. Spinal dysraphism: Trends in Northern India Journal: Paediatric Neurosurgery - Pediat Neurosurg. Vol. 38, No. 3, Pp. 133-145, 2003.

4. Tahira Nishtar, Attiya Elahi, Naveed Iqbaletal. To determine the frequency of accuracy of MRI in diagnosis of rare disorder of spinal dysraphism. J Med Sci (Peshawar, Print) October 2011; Vol 19, No 4: 195-199.

5. Zuppani HB ${ }^{1}$, Guedes Bde V, da Silva CJ, et al. Lipomyelocele with osseous dysraphic hamartoma in a child: a case report. J Pediatr Orthop B. 2010 Jul;19(4):382-4. doi: 10.1097/BPB.0b013e3283345ddb. 